- Both articaine and lignocaine show poor diffusion to the palate, causing pain during palatal injection. This paper provides information for giving patients the best, least painful injection without relying solely on the possible diffusion properties of the anaesthetic.

- A comparison between articaine and lignocaine gives important information about articaine.

- The relationship between price and benefit may be important in countries where there is a difference in cost between articaine and lignocaine.

\title{
Articaine and lignocaine efficiency in infiltration anaesthesia: a pilot study
}

\author{
P. C. Oliveira, ${ }^{1}$ M. C. Volpato, ${ }^{2}$ J. C. Ramacciato ${ }^{3}$ and J. Ranali ${ }^{4}$
}

\begin{abstract}
Aim The purpose of this study was to evaluate the onset of action of pulpal and soft tissue anaesthesia, and pain experience after buccal and palatal infiltrative injections with 4\% articaine with 1:100,000 adrenaline, and 2\% lignocaine with 1:100,000 adrenaline.

Method A double blind cross-over study was conducted with 20 healthy adult subjects who, in two appointments at least two weeks apart, randomly received an infiltration anaesthesia with the solutions in the buccal and palatal regions of the upper right canine. The tooth was tested with a pulp tester before (to establish its baseline response), and after the injection, until return to the base threshold level. The pain experience caused by palatal injection was verified by the visual analogue scale (VAS). Data were analysed using Wilcoxons test $(\alpha=0.05)$.

Results There were no significant statistical differences between the solutions with respect to VAS $(p=0.45)$, onset of action $(p=0.80)$ and pulpal $(p=0.08)$ and soft tissue $(p=0.18)$ anaesthesia duration, although pulpal anaesthesia may have reached statistical significance if a higher number of volunteers had been used.

Conclusion Under the conditions of this study it can be concluded that both anaesthetic solutions showed similar pain experience.
\end{abstract}

Pain control in dentistry is an important factor, to reduce the fear and anxiety associated with dental procedures. Better local anaesthesia and treatment techniques may decrease cardiovascular risk caused by anxiety and improve the dental treatment.

Among the several commercially available anaesthetic solutions, lignocaine is the most frequently used in dentistry, being the standard for comparison. It is an amide anaesthetic with a short onset of action and an intermediate duration of anaesthesia when associated with adrenaline. ${ }^{1}$

Articaine is also classified as an amide anaesthetic with anaesthetic efficacy similar to lignocaine. The presence of a tiophene ring increases its liposolubility and potency ${ }^{2}$ and according to

\footnotetext{
${ }^{1}$ Graduate Student, ${ }^{2}$ Associate Professor, ${ }^{3}$ Graduate Student, ${ }^{4 *}$ Chairman Professor, Dentistry School of Piracicaba, State University of Campinas.

*Correspondence to: José Ranali, Faculdade de Odontologia de Piracicaba / UNICAMP, Departamento de Ciências Fisiológicas, Avenida Limeira, 901, C.P. 52, 13414-903, Piracicaba, São Paulo, Brazil

Email:jranali@fop.unicamp.br
}

\section{Refereed paper}

Received 17.12.02; Accepted 20.08.03

doi:10.1038/sj.bdj.4811422

๑ British Dental Journal 2004; 197: 45-46 some authors ${ }^{3,4}$ its ability to diffuse can produce pulpal anaesthesia in mandibular teeth after infiltration anaesthesia, as well as palatal anaesthesia after maxillary buccal infiltration.

Although Haas et $a .^{5}$ did not find any statistical difference between articaine and prilocaine with respect to palatal anaesthesia, there is no study comparing articaine and lignocaine, both with 1:100,00 adrenaline.

The purpose of this study was to evaluate the anaesthetic efficacy and pain experience after buccal maxillary and palatal infiltration of $2 \%$ lignocaine and $4 \%$ articaine, both with 1:100,000 adrenaline.

\section{MATERIAL AND METHOD}

A double blind cross-over study was conducted with 20 healthy adult subjects ( 16 women and 4 men) ranging in age from 20 to 39 years (average age 26 years). None of the subjects were taking any medication that would alter pain perception. The study was approved by the Ethical Committee in Human Research at Dentistry School of Piracicaba, State University of Campinas; written informed consent was obtained from each subject.

During two separate appointments the subjects randomly received an infiltration of $1.8 \mathrm{ml}$ of 2\% lignocaine with 1:100,000 adrenaline (Alphacaine, DFL Indústria e Comércio Ltda, Rio de Janeiro, RJ) and 4\% articaine with 1:100,000 adrenaline (Septanest, Septodont, France). Carpule syringe with a previous aspiration device (Duflex, S.S.White, Rio de Janeiro, RJ) and short needles $30 \mathrm{G}$ (BD - Brasil, São Paulo, SP) were used.

To avoid the influence of the menstrual cycle on pain experience, ${ }^{6}$ the appointments were spaced 28 days apart for women. The interval for male subjects was 15 days.

All injections were accomplished by one dentist, with slow injection (approximately $1 \mathrm{ml} \mathrm{min}{ }^{-1}$ ), resulting in greater safety and reduced trauma. A buccal maxillary infiltration in the upper right canine region was performed with $1.8 \mathrm{ml}$ of the solution and, after 5 minutes, $0.35 \mathrm{ml}$ was injected in the palate.

At the beginning of each appointment and before the injection, the upper right canine was tested nine times with the pulp tester (model 2006; Analytic Technology Corp, Redmond, WA) to record baseline vitality. According to the manufacturer's recommendation, a small portion of fluoride gel was applied to the probe tip, which was placed on the vestibular side, midway between the gingival margin and the occlusal edge of the tooth. 


Table 1 Median (range) to onset of action and pulpal and soft tissue anaesthesia (in minutes) and palatal pain sensitivity (in cm) with articaine and
lignocaine solutions.
\begin{tabular}{llll}
\hline Anaesthetic solution & Onset of action $(\mathrm{min})$ & Pulpal anaesthesia (min) & Soft tissue anaesthesia (min) \\
\hline 4\% articaine with 1:100,000 adrenaline & $1.0(1.0-13.0)$ & $67.0(27.0-117.0)$ & $238.5(168.0-308.0)$ \\
$2 \%$ lignocaine with 1:100,000 adrenaline & $3.0(1.0-7.0)$ & $46.5(25.0-107.0)$ & $227.5(159.0-273.0)$
\end{tabular}

Every two minutes after the end of the buccal injection, the tooth was tested until there was no response from the subject to the maximum output (80 reading) of the pulp tester. The response to the pulp test is characterised as a subjective sensation, such as pulsation, tingling or pain. Onset of action was considered as the period between the end of the injection and the first of two consecutive readings of 80 without response. After this period the tooth was tested every 10 minutes until readings returned to the baseline threshold. Pulpal anaesthesia was defined as the period in which the subject had no response to the maximal output of the pulp tester ( 80 reading).

Each subject was asked to record the time of return to normal sensation in the upper lip (soft tissue anaesthesia).

The pain experience (palatal pain sensitivity) caused by palatal injection was recorded using the visual analogue scale (VAS), ranging from $0=$ 'no pain' to $10=$ 'worst pain imaginable'.

Onset pulpal anaesthesia and VAS data were analysed nonparametrically using Wilcoxon test because the data did not meet normality assumptions. Comparisons were considered significant at $\mathrm{p}<0.05$.

\section{RESULTS}

There were no significant differences between articaine and lignocaine solutions with respect to onset of action $(p=0.80)$ and pulpal $(p=0.08)$ and soft tissue $(p=0.18)$ anaesthesia duration (Table 1$)$.

The average VAS scores are illustrated in Table 1 . These scores indicate that articaine and lignocaine have similar behaviour $(\mathrm{p}=0.45)$.

\section{DISCUSSION}

Many studies have compared the anaesthetic efficiency of articaine and other anaesthetic solutions. Hass et $a l^{5}$ did not find any differences between articaine and prilocaine solutions in maxillary infiltration anaesthesia. Similarly, Vahatalo et al. ${ }^{7}$ did not find any differences between articaine and lignocaine, although the solutions had different concentrations of adrenaline. In a clinical multi-centre study, which included patients of different ages and treatment necessities, Malamed et $a .^{2}$ also did not find any difference between articaine and lignocaine, both with 1:100,000 adrenaline, concluding that both solutions were appropriate for clinical use and comparable with respect to onset and duration of anaesthesia. The pain relief provided by both solutions was similar.

Although the pulpal anaesthesia values did not present a statistically significant difference ( $\mathrm{p}=0.08$ ), the difference (in minutes) between articaine and lignocaine may be of clinical significance, as can be seen in Table 1 (median: lignocaine 46.5; articaine 67.0). Studies with larger numbers of subjects are necessary to evaluate and validate this hypothesis.

Haas et $a l .{ }^{5}$ did not observe palatal anaesthesia even after 25 minutes of buccal infiltration of articaine. However, even today clinicians claim that palatal anaesthesia can be less painful after the use of articaine at the buccal side.
Pain measurement is difficult to establish, because its perception and intensity are multifactorial, encompassing sensorial and affective factors. ${ }^{8,9}$ Although the VAS may show deficiencies regarding understanding (especially related to old age) and precision, ${ }^{10,11}$ it provides a validated and meaningful measure of anaesthetic efficiency, ${ }^{12}$ being used for this purpose by many authors. ${ }^{2,12,13,14,15}$

This investigation not only ratified the results obtained by the mentioned authors ${ }^{2,5,7}$ with respect to anaesthetic efficiency, but also showed that there were no differences between the solutions with respect to palatal pain sensitivity to injection five minutes after infiltration at the buccal side, which could be seen from the values of 2.3 and 2.7 for VAS, respectively for articaine and lignocaine. Therefore, the statement that articaine has a better diffusion than the other local anaesthetics used in dentistry, was not evident in this study.

\section{CONCLUSION}

Under the conditions of this controlled randomised double-blind study there were no differences between articaine and lignocaine in relation to palatal pain sensitivity.

The anaesthetic efficacy seemed to be similar, although the values were near to statistical (and also probably clinical) significance, with a tendency for articaine having increased duration of pulpal anaesthesia. Studies with larger number of subjects are necessary to evaluate and validate this hypothesis.

This study was supported by FAPESP (99/12005-8 and 99/11993-1).

1. Malamed S F. Handbook of local anesthesia. 4th ed. St. Louis: Mosby - Year Book, 1997, pp 63-64.

2. Malamed S F, et al. A comparision between articaine $\mathrm{HCl}$ and lidocaine $\mathrm{HCl}$ in pediatric dental patients. Ped Dent 2000; 22: 307-311.

3. Lipp M, Daublander M. The German experience of articaine. In: Proceedings of the international symposium on local analgesia in dentistry. London: Faculty of General Dental Practitioners, 1999, 21-22.

4. Sloss D R. Articaine in dental practice. In: Proceedings of the international symposium on local analgesia in dentistry. London: Faculty of General Dental Practitioners, 1999, 23-24.

5. Hass D A, et al. Comparison of articaine and prilocaine anesthesia by infiltration in maxillary and mandibular arches. Anesth Prog 1990; 37: 230-237.

6. Goolkasian P. Cyclic changes in pain perception: an ROC analysis. Percept Psychophys 1980; 27: 499-504.

7. Vahatalo $K_{1}$ Antila $H$, Lehtinen $R$. Articaine and lidocaine for maxillary infiltration anaesthesia. Anesth Prog 1993; 40: 114-116.

8. Joyce $C R B$, et al. Comparasion of fixed interval and visual analogue scales for rating chronic pain. Eur J Clin Pharmacol 1975; 8: 415-420.

9. Kremer $E_{1}$ Hampton Atkinson J, Ignelzi R J. Measurement of pain: patient preference does not confound pain measurement. Pain 1981; 10: 241-248.

10. Jensen M P, Karoly P, Braver S. The measurement of clinical pain intensity: a comparasion of six methods. Pain 1986; 27: 117-126.

11. Newton JT, Buck D J. Anxiety and pain measures in dentistry: a guide to their quality and application. JAm Dent Assoc 2000; 131: 1449-1457.

12. Malamed $S F$, Gagnon $S$, Leblanc D. Efficacy of articaine: a new amide local anesthetic. JAm Dent Assoc 2000; 131: 635-642.

13. Meechan J G, Blair G S. The effect of two different local anesthetic solutions on pain experience following apicectomy. Br Dent J 1993; 175: 410-413.

14. Primosch R E, Brooks R. Influence of anesthetic flow rate delivered by the Wand Local Anesthetic System on pain response to palatal injections. Am J Dent 2002; 15: 15-20.

15. Meechan J G. A comparision of ropivacaine end lidocaine with epinephrine for intraligamentary anesthesia. Oral Surg Oral Med Oral Pathol Oral Radiol Endod 2002; 93: 469-473. 